\title{
Validation of black-box performance models for a water-to-water heat pump operating under steady state and dynamic loads
}

\author{
Elena Fuentes ${ }^{1}$, and Jaume Salom ${ }^{1 *}$ \\ ${ }^{1}$ Catalonia Institute for Energy Research (IREC), Energy Efficiency in Systems, Buildings and Communities Group, Jardins de les Dones \\ de Negre 1, 2a 08930 Sant Adrià de Besòs (Barcelona), Spain
}

\begin{abstract}
The use of simple mathematical models for describing the behaviour of heat pumps is important for assessing the energy performance of this equipment when installed in buildings. However, because of their simplicity, commonly used simple models, may not be able to fully account for the dynamic performance of heat pumps during transient phases. In this study, different performance black box models for an on-off water-to-water heat pump are validated by comparison with laboratory experimental results at steady state and dynamic cycling conditions. The models range from the solution based on the interpolation on the heat pump performance map to the detailed dynamic solution that combines correlations for the quasi-steady state operation and activation functions to model the transient phases. The output temperatures, electrical and thermal power and coefficient of performance from simulations were compared with experimental data from a water-to-water heat pump of $40.5 \mathrm{~kW}$ nominal heating capacity operating under cycling conditions. After validation with experiments, annual energy performance simulations of a tertiary building provided with a heat pump were conducted. These simulations quantifying the uncertainty expected when using heat pump performance models in simulation environments for estimating their annual energy performance.
\end{abstract}

\section{Introduction}

The increasing implementation of heat pumps for building climatization is expected to contribute significantly to the mitigation of $\mathrm{CO}_{2}$ emissions through the achievement of energy savings. A consequence of the rapid growth in the number of the heat pump installed in buildings is the need for developing novel integration strategies for demand side management applications. The development of such integration strategies requires the use of simulation tools models that integrate the different components interacting in energy grids, including the simulation of heat pump systems. Using black box models to simulate heat pumps behaviour offers a practical solution that provides sufficient level of detail while using a limited number of parameters, without the need for solving complex physics models and obtaining detailed system information.

The most commonly used black-box models that are implemented in dynamic simulation software are the socalled quasi-steady state performance map models [1]. These models, which are based on performance data from manufacturers', calculate the heat pump performance at each simulation time step by means of interpolation/extrapolation algorithms. Alternatively these models use polynomials fitted to the performance map data as a function of the operating temperatures of the heat pump. Typical implementations of quasi-steady state performance map models for heat pumps in the simulation software package TRNSYS are types 927, 504, 505, 665 and 668 from the TRNSYS and TESS libraries $[2,3]$.

However, because of their simplicity, these performance map models may not be able to fully account for the dynamic behaviour of on-off heat pump systems, particularly during transient phases such the start-up and shut-down periods, which may have an influence on the system efficiency [4-6]. Other dynamic effects, such as icing/defrosting and thermal inertial effects on evaporator and condenser are not accounted for by these models [1]. Another potential issue of using the performance state models is the need for extrapolating system operation beyond the range of the available temperature map information. According to previous studies, extrapolation methods need to be carefully evaluated since the performance gradients outside the available performance map may significantly deviate from real gradients [7].

\footnotetext{
Corresponding author: jsalom@irec.cat
} 
Previous analysis on the validation of quasi-steady performance heat pump models with field data has shown substantial deviation between the steady-state estimations and real dynamic performance resulting from parasitic losses [5]. Although this influence is expected to be important for fixed capacity-heat pumps, it might be relevant also for inverter driven heat pumps at low loads that yield compressor frequencies below the minimum threshold for inverter modulation.

Although some previous studies have analyzed the output of heat pump performance map models [7], no previous studies have compared these methods between them to assess their validity to predict heat pump efficiency. Within this context, in this study different heat pump performance models for an on-off water-towater heat pump are validated by comparison with laboratory experimental results at steady state and dynamic cycling operating conditions. The models studied range from the simplest solution based on the interpolation of the heat pump performance as a function of the inlet temperatures to evaporator and condenser to the more detailed dynamic solution that combines a regression model for the heat pump quasi-steady state operation and activation functions for the start-up phases. In a first stage, the system performance obtained from the models is compared with experimental data for validation. Secondly, annual simulations are conducted to assess the models' uncertainty to predict annual performance profiles.

\section{Methodology}

\subsection{Experimental study}

Laboratory experiments were conducted with an on-off water-to-water heat pump of $40.5 \mathrm{~kW}$ nominal heating capacity. The heat pump was tested in a laboratory that allowed operating the equipment in a hardware-in-theloop configuration. The experimental set up consisted of two thermal test benches used to emulate the heat exchange with the ground and a virtual storage tank of $1000 \mathrm{~L}$ volume connected to a heating load (Fig. 1). The thermal test benches are provided with flow and temperature sensors in a control system that allows emulating the thermal loads and the heat source of the heat pump. For the emulation the test benches are connected to two external heating and cooling circuits used to control the return temperatures to the evaporator and condenser of the heat pump. The water flow rates through evaporator and condenser were set to constant values of 5.9 and $6.3 \mathrm{~m}^{3} / \mathrm{h}$, respectively, and were controlled with a three-way electronic valve connected to an external by-pass and an induction flow meter.
The virtual tank, heat source and load were simulated using the TRNSYS software. The tank model used (type 534), from the TESS component libraries is a detailed model for a stratified tank previously validated by Allard and Kummert [8]. Two port flows were defined for the tank model, one of them connected to a fixed thermal heating load and a second flow that was connected to the condenser of the heat pump. The dimensions and insulation properties of the tank were obtained from manufacturer catalogue data. The inlet temperature to the evaporator was kept at $15{ }^{\circ} \mathrm{C}$. Different fixed heating load levels between 8 and $40.5 \mathrm{~kW}$ applied on the virtual storage tank were emulated in order to characterize the heat pump performance at different load ratios (PLR), from steady operation to cycling conditions.

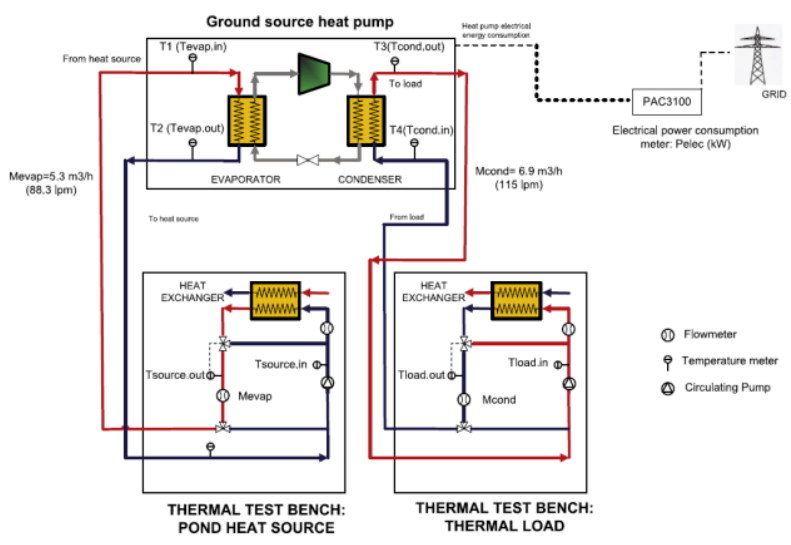

Fig. 1. Experimental set up for laboratory testing

\subsection{Performance map models evaluated}

The different models compared in this study are listed in Table 1. Model A is based on the application of TRNSYS type 927 for the quasi-steady state periods, using a look-up table performance map interpolation method [3]. This Type is combined with a postcorrection that is applied on the results from simulations to account for partial load performance degradation, as in the method by Magraner et al. [4]. For the postcorrection, the coefficient of performance (COP) integrated on the chosen analysis period is multiplied by the partial load factor (PLF). The PLF factor is determined from the integrated load ratio (PLR) that corresponds to such period (Table 1). Three variations of the correction are applied, two based on correction equations from EN14825 [9], and another one that accounts for both the start-up and stand-by loss coefficients $\mathrm{Cc}$ and $\mathrm{Cd}$ [5]. For the application of EN 14825 corrections, default values for the coefficients $\mathrm{Cc}$ $(0.90)$ and $\mathrm{Cd}(0.25)$ where adopted, while experimental values for these coefficients were used for the correlation from Fuentes et al. $(\mathrm{Cc}=0.988 ; \mathrm{Cd}=0.1)$ [5]. A case without any correction for part load degradation $(\mathrm{PLF}=1)$ is also considered for model A. 
Model B applies Type 927 to calculate the quasi-steady state performance combined with an instantaneous correction on the COP values to account for part load transient effects by means of Type43a. This latter Type applies the partial load factor correction using look up tables created with pair of PLR-PLF values obtained with the PLF equations.

Table 1. Heat pump model variations considered for the study

\begin{tabular}{|c|c|c|}
\hline Model & $\begin{array}{l}\text { Integrating } \\
\text { submodels }\end{array}$ & Model variations \\
\hline \multirow{4}{*}{$\begin{array}{c}\text { Model } \\
\text { A }\end{array}$} & $\begin{array}{l}\text { Quasi-steady } \\
\text { state: Type } 927 \\
\text { based on } \\
\text { manufacturer } \\
\text { data }\end{array}$ & $P L F=1$ \\
\hline & \multirow{3}{*}{$\begin{array}{c}\text { Transient } \\
\text { states: Post- } \\
\text { processing with } \\
\text { PLF correction } \\
\text { on integrated } \\
\text { COP }\end{array}$} & $\begin{array}{c}P L F=P L R /(C c P L R+(1-C c)) \\
(1)\end{array}$ \\
\hline & & $P L F=1-C d(1-P L R)$ \\
\hline & & $\begin{array}{c}P L F=1 /(1+(C d(1-P L R) /(1-C d \\
(1-P L R))+(1-C c)(1- \\
P L R) / P L R))(3)\end{array}$ \\
\hline \multirow{4}{*}{$\begin{array}{l}\text { Model } \\
\text { B }\end{array}$} & $\begin{array}{c}\text { Quasi-steady } \\
\text { state: Type } 927 \\
\text { based on } \\
\text { manufacturer } \\
\text { data }\end{array}$ & $P L F=1$ \\
\hline & \multirow{3}{*}{$\begin{array}{c}\text { Transient } \\
\text { states: Type } \\
\text { 43a, PLF } \\
\text { correction on } \\
\text { instantaneous } \\
\text { COP }\end{array}$} & $\begin{array}{c}P L F=P L R /(C c P L R+(1-C c)) \\
(1)\end{array}$ \\
\hline & & $P L F=1-C d(1-P L R)$ \\
\hline & & $\begin{array}{c}P L F=1 /(1+(C d(1-P L R) /(1-C d \\
(1-P L R))+(1-C c)(1- \\
P L R) / P L R))(3)\end{array}$ \\
\hline \multirow{5}{*}{$\begin{array}{l}\text { Model } \\
\text { C }\end{array}$} & $\begin{array}{l}\text { Quasi-steady } \\
\text { state: } \\
\text { Regression } \\
\text { equations } \\
\text { based on full } \\
\text { capacity } \\
\text { experiments [5] }\end{array}$ & $\begin{array}{l}\text { Qcond }=c+d \text { Tevap.in }+e \\
\text { Tcond.in } \\
\text { Qevap }=f+g \text { Tevap.in }+i \\
\text { Tcond.in } \\
\text { Pelec }=j+k \text { Tcond.in }+l \\
\text { Tcond.in }{ }^{2}\end{array}$ \\
\hline & $\begin{array}{l}\text { Stand-by } \\
\text { transient state: } \\
\text { Residual } \\
\text { electrical } \\
\text { consumption }\end{array}$ & $0.02 \mathrm{~kW}$ \\
\hline & \multirow{3}{*}{$\begin{array}{c}\text { Start-up } \\
\text { transient state: } \\
\text { Activation } \\
\text { function on } \\
\text { condenser } \\
\text { thermal power }\end{array}$} & $\left.f_{\text {sigmoid }}=1 /\left[1+\exp \left(t_{50}-t\right) / s\right)\right](7)$ \\
\hline & & $f_{\exp }=1 /[1+\exp (-t / \tau)]$ \\
\hline & & $\begin{array}{c}f_{\text {polyn }}=b_{6} t^{6}+b_{5} t^{5}+b_{4} t^{4}+b_{3} t^{3}+b_{2} t^{2} \\
+b_{1} t\end{array}$ \\
\hline
\end{tabular}

Model $\mathrm{C}$ is comprised of regression functions to calculate the quasi-steady thermal and electrical power rate with input of the operating temperatures. The parameters of the equations have been obtained by fitting these to the performance map data. The parasitic effect caused by the stand-by consumption is modeled by setting a residual electrical power consumption during stand-by operation of $20 \mathrm{~W}$, as determined experimentally. The circulating pumps are external to the heat pump, therefore this electrical consumption is due to the residual consumption of the electronic circuits of the heat pump on sleep mode. For the start-up phases in model $\mathrm{C}$, three different possible activation functions are tested (Table 1), following a polynomial, exponential or sigmoid shape for the condenser heat rate. In the exponential function, $\tau$ is a time constant that represents the time from the onset of the start-up required to reach $63.2 \%$ of the quasi-steady state nominal heating capacity. In the sigmoid function $\mathrm{t}_{50}$ is the time required to achieve $50 \%$ of the nominal heating capacity and $s$ is a length parameter of the sigmoid function. The electrical power is assumed to reach instantly its nominal value at the onset of the start-up period $[5,6,10]$ and the evaporator thermal energy rate during the start-up is calculated from the energy rate balance between the condenser thermal power and the electrical power consumption of the heat pump.

In all the models tested, the inner control thermostat of the heat pump was simulated. In the case of model A and $\mathrm{B}$, the thermostat was modeled with Type 1502. In the case of model $\mathrm{C}$, the thermostat operation was included in the heat pump model code itself. In all cases the inner control of the heat pump was configured to a condenser return temperature set point of $49.0^{\circ} \mathrm{C}$ with a dead band of $2.0^{\circ} \mathrm{C}$.

\subsection{Methods for models validation and annual performance simulations}

For comparison with experimental data, the quasi-steady state models described above were implemented on a simple simulation environment using the software TRNSYS. This environment comprised a fixed load connected to a storage tank of $1000 \mathrm{~L}$ volume (Type 534) that in turn is connected to the heat pump model. The temperature of the water circuit from the ground to the inlet of the evaporator was kept constant at a value of $15{ }^{\circ} \mathrm{C}$. Simulations were performed at diverse partial load ratios in order to reproduce the experiments conducted in the laboratory, with a timestep of $10 \mathrm{~s}$. The data obtained from the simulations were compared with integrated hourly COP values obtained during the experiments.

Once the performance of the models was compared with the experimental data, these were implemented in a TRNSYS environment that included a lump capacity building model that is heated up by means of a radiators heating distribution system. This environment was used in order to conduct dynamic annual simulations in a more complex setting, using a time step of $10 \mathrm{~s}$. 
Table 2. Main components of TRNSYS building model used for annual simulations

\begin{tabular}{|c|c|c|}
\hline Type & Definition & Parameters \\
\hline 15 & Meteo data & $\begin{array}{l}\text { Collected meteorological station } \\
\text { data from la Rochelle (France) }\end{array}$ \\
\hline 574 & $\begin{array}{l}\text { Internal gains } \\
\text { from } \\
\text { occupants }\end{array}$ & $\begin{array}{l}\text { Activity level: seated, light } \\
\text { work, typing }\end{array}$ \\
\hline $14 \mathrm{a}$ & $\begin{array}{l}\text { Occupancy } \\
\text { profile }\end{array}$ & $\begin{array}{l}\text { Number of occupants and } \\
\text { occupancy schedule according } \\
\text { to building survey data }\end{array}$ \\
\hline $18 \mathrm{a}$ & $\begin{array}{l}\text { Lump } \\
\text { capacity } \\
\text { building }\end{array}$ & $\begin{array}{l}\text { Building loss coefficient: } 0.3921 \\
\text { W/m K } \\
\text { Building capacitance: } 814666 \\
\mathrm{~kJ} / \mathrm{K} \\
\text { Building surface area: } 2753 \mathrm{~m}^{2} \\
\text { Building volume: } 5666 \mathrm{~m}^{3}\end{array}$ \\
\hline 1231 & $\begin{array}{l}\text { Radiators } \\
\text { system }\end{array}$ & $\begin{array}{c}\text { Design capacity: } 43 \mathrm{~kW} \\
\text { Design surface temp.: } 50{ }^{\circ} \mathrm{C} \\
\text { Design delta T exponent: } 1.28\end{array}$ \\
\hline 1502 & $\begin{array}{l}\text { Room control } \\
\text { thermostat on } \\
\text { radiators } \\
\text { circuit }\end{array}$ & $\begin{array}{l}\text { Set point: } 20^{\circ} \mathrm{C} \\
\text { Dead band: } 2{ }^{\circ} \mathrm{C}\end{array}$ \\
\hline 1250 & $\begin{array}{l}\text { Heating curve } \\
\text { control on } \\
\text { radiators } \\
\text { circuit supply } \\
\text { temperature }\end{array}$ & $\begin{array}{l}\text { Low design temp..: }-2.1^{\circ} \mathrm{C} \\
\text { Low ambient set point: } 49^{\circ} \mathrm{C} \\
\text { High design temp..: } 20^{\circ} \mathrm{C} \\
\text { High ambient set point: } 30^{\circ} \mathrm{C}\end{array}$ \\
\hline 649 & $\begin{array}{l}\text { Tempering } \\
\text { valve }\end{array}$ & $\begin{array}{l}\text { Valve to mix hot water from } \\
\text { tank with return temperature } \\
\text { from radiators. Set point } \\
\text { temperature given by heating } \\
\text { curve control (type 1250) }\end{array}$ \\
\hline 534 & $\begin{array}{l}\text { Hot storage } \\
\text { tank }\end{array}$ & $\begin{array}{c}2 \text { ports, } 4 \text { nodes } \\
1000 \mathrm{~L} \text { volume } \\
\text { Heat loss coefficient: } 2.06 \mathrm{~kJ} / \mathrm{h} \\
\mathrm{m}^{2} \mathrm{~K}\end{array}$ \\
\hline 557 & $\begin{array}{c}\text { Borehole heat } \\
\text { exchanger }\end{array}$ & $\begin{array}{c}\text { Storage volume: } 5062 \mathrm{~m}^{2} \\
\text { Borehole depth: } 50 \mathrm{~m} \\
\text { Number of boreholes: } 13 \\
\text { Storage thermal conductivity: } \\
1.43 \mathrm{~W} / \mathrm{m} \mathrm{K} \\
\text { Storage heat capacity: } 2400 \\
\mathrm{~kJ} / \mathrm{m}^{3} \mathrm{~K} \\
\text { Outer radius U pipe: } 0.016 \mathrm{~m} \\
\text { Inner radius U pipe: } 0.0131 \mathrm{~m} \\
\text { Fill thermal conductivity: } 2 \\
\text { W/mK } \\
\text { Pipe thermal conductivity: } 0.42 \\
\mathrm{~W} / \mathrm{m} \mathrm{K} \\
\text { Flowrate: } 530.8 \mathrm{~kg} / \mathrm{h} \\
\text { Thermal conductivity of layer: } \\
1.43 \mathrm{~W} / \mathrm{mK} \\
\text { Heat capacity: } 2400 \mathrm{~kJ} / \mathrm{m}^{3} \mathrm{~K}\end{array}$ \\
\hline
\end{tabular}

The virtual building comprises a section of an office of $2753 \mathrm{~m}^{2}$ whose technical and occupation characteristics are based on a real building in la Rochelle (France) [10]. The building is heated in the cold season by means of a radiator distribution system connected to a heat pump identical to the one used in the present study. In the simulation model the condenser of the heat pump is connected to a hot tank of $1000 \mathrm{~L}$ that provides heat to the radiators distribution system. The heat supplied to the radiators is controlled by mixing the outlet temperature from the hot tank and the return water from the radiators by means of a tempering valve. The set point temperature of the water to the radiators is given by a heating curve control, which specifies the set point supply temperature as a function of the outdoor temperature. The evaporator of the heat pump is connected to a borehole that provides heat from the ground. The borehole and ground properties have been defined using as reference the parameters defined in Magraner et al. (2011) [4]. A summary of the main components included in the annual simulation environment are described in Table 2.

\section{Results}

\subsection{Models validation with experimental data}

As described in previous sections, the integrated COP per hour obtained from the models at different loads was compared with results from. Figure 2 shows the results obtained with model A variations in comparison with experimental data. In order to quantify the importance of the transient phases, experimental performance data without stand-by losses was also calculated by subtracting the stand-by residual consumption from the measurement of electrical power consumption during stand-by. Comparison between the results without performance losses (Model A, PLF=1) and the experimental results show that transient operation cause relevant parasitic degradation. The start-up losses can produce a degradation of the COP up to $8.6 \%$, while all losses together degrade the COP up to $14 \%$. As expected, degradation is more important with decreasing loads ratios, as the length of the stand-by periods increases with decreasing heating needs [5].

The best results for model $\mathrm{A}$ are obtained for the PLF correction as a function of both $\mathrm{Cd}$ and $\mathrm{Cc}$. Larger discrepancy with respect to the experimental data is obtained with the equations that consider only one coefficient with default values from EN14825 [9]. The best performance for the two coefficients correction model is due to the fact that it considers their actual experimental values instead of the default values in the 
EN14825 standard [9].

The results from model B (Type 927 combined with the instantaneous correction of the COP through Type 43a), are illustrated in Figure 3.

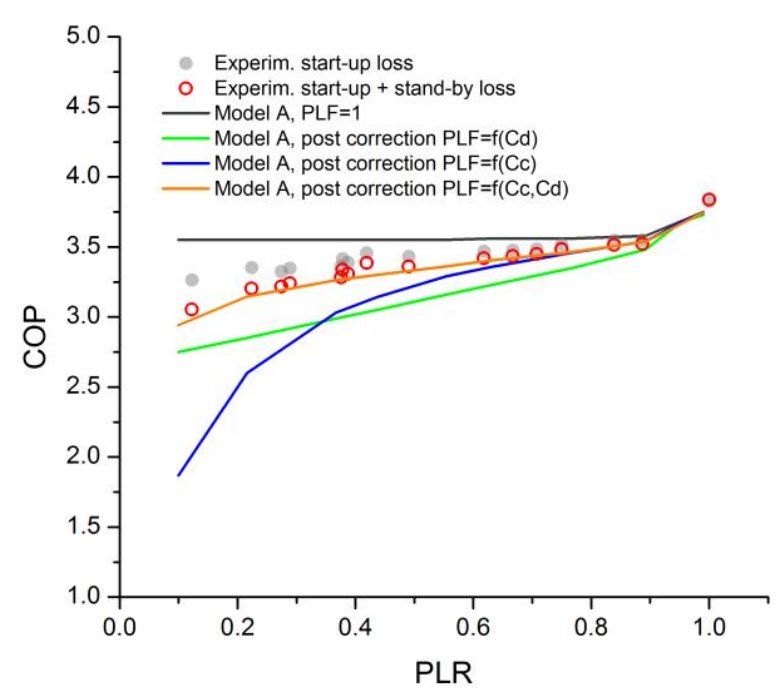

Fig. 2. Comparison of experimental and simulated hourly COP for variations of model A (Type 927 with post-correction)

The best results for model $\mathrm{B}$ are obtained when the correction is formulated as a function of the two loss coefficients, while the highest deviation is obtained for the model based on the $\mathrm{Cd}$ factor, which underpredicts the COP values up to $8 \%$ over the whole range of partial load ratios.

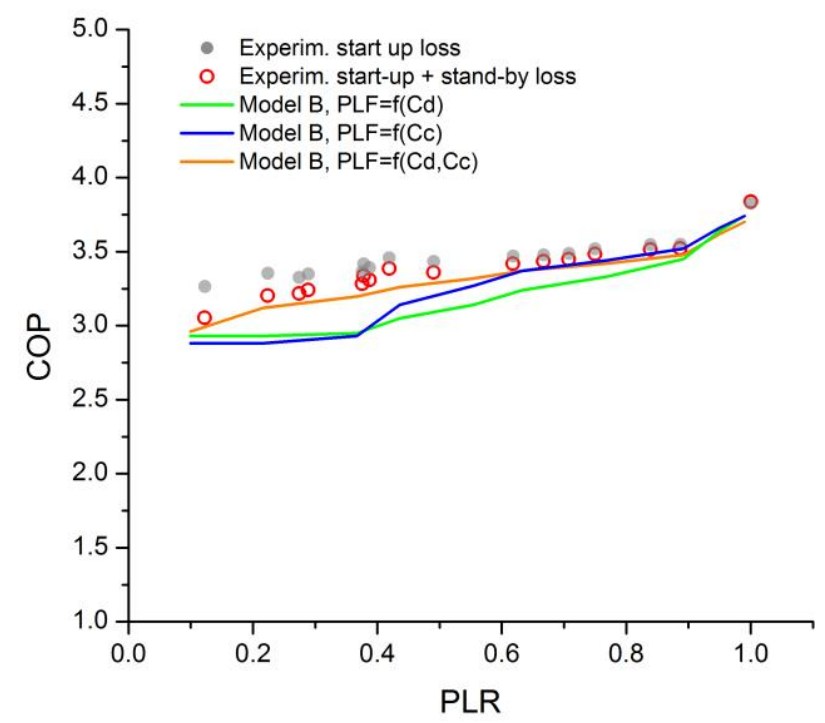

Fig. 3. Comparison of experimental and hourly COP for variations of model B (Type 927 with instantaneous correction)

The results obtained with model $\mathrm{C}$ are represented in Figure 4 . The output from this model is very close to the experimental data, without significant differences between the activation functions applied. This indicates that although the start-up period has an influence, the exact shape of the start-up function during the activation of the heat pump is not significant on the resulting performance.

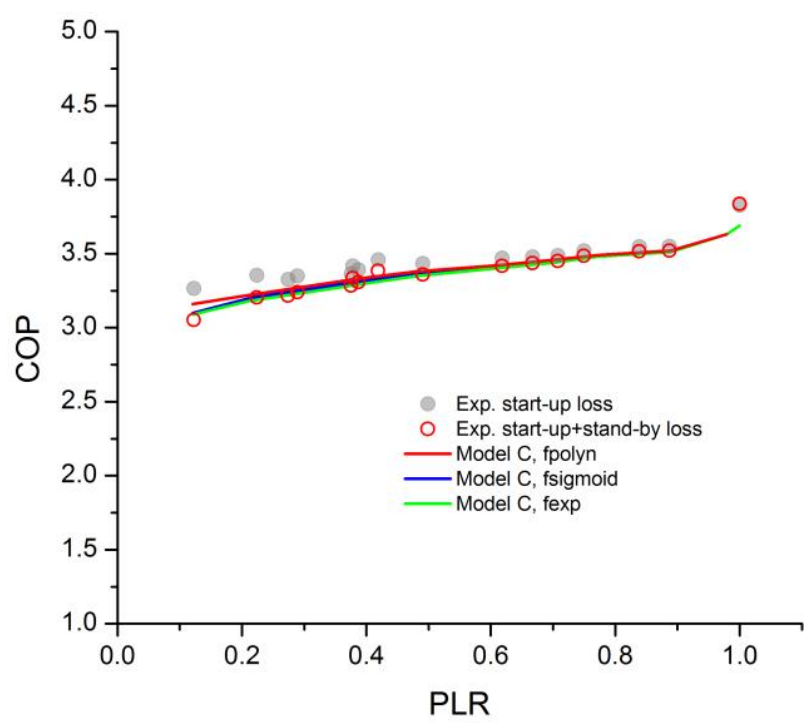

Fig. 4. Comparison of experimental and hourly COP for variations of model $\mathrm{C}$ (regression model combined with activation function)

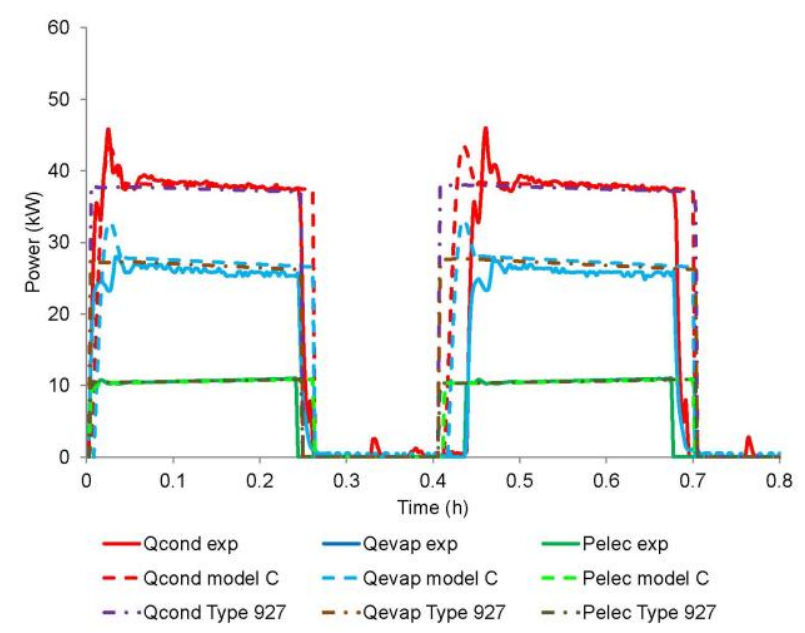

Fig. 5. Simulated and experimental thermal and electrical power at 0.55 partial load ratio. The models evaluated are type 927 and model $\mathrm{C}$ (regression with polynomial function). Qcond: thermal power condenser; Qevap: Thermal power evaporator; Pelec : electrical power consumption

When comparing the thermal and electrical power during transient operation from the two models considered here (Fig. 5) it is seen that model $\mathrm{C}$ better matches the shape of the condenser energy rate than Type 927 (steady state model in models A and B). The time shift between models and experiments is due to the inertial effects not fully reproduced by the simulation models. The condenser thermal power from Type 927 rise faster than the experimental data because this model considers that the heat pump reaches its maximum nominal heating 
capacity value at the onset of the start-up. Regarding the electrical power consumption, during the on periods both simulation models give good results since the nominal electrical consumption at the onset of the start-up is reached instantaneously. On the other hand, during startup both model $\mathrm{C}$ and Type 927 overestimate the evaporator thermal power. In the case of model $\mathrm{C}$, this is because the thermal power is calculated from the energy balance between the evaporator and condenser. However, the results show that this is a hypothesis that while it is valid during steady operation it does not hold during the start-up period. Although some further improvements should be applied on model $\mathrm{C}$ to better match the experimental data at the evaporator, it can be concluded that model $\mathrm{C}$ best represents both the instantaneous dynamic behavior of the condenser and the coefficient of performance. For this reason, in the next section model $\mathrm{C}$ will be used as a reference to assess the annual performance of the other models evaluated.

\subsection{Dynamic annual performance evaluation}

The results of daily COP obtained from the annual simulations with the different models are shown in Figures 6 and 7 during the periods of heating demand. The periods in which the load is zero are no considered for the analysis since during these periods the heat pump is inactive. The dynamic profiles are compared with reference results obtained from model $\mathrm{C}$ based on the polynomial activation function. This model is used as a reference since it was concluded in the validation section that it closely reproduces the heat pump dynamic behaviour. It should be noted that the influence of the activation function of model $\mathrm{C}$ on the results has been found to be negligible, hence, the selection of the activation function is irrelevant for the calculations.

The results of model A, with PLF=1 (Figure 6), show that the uncorrected model performs well during the high load periods (eg. days 1 to 60 ), while it overpredicts the performance of the heat pump during periods of low loads (eg. days 100 to 150), with respect to the output from the reference model $\mathrm{C}$. For the versions of model $\mathrm{A}$ that applied a PLF correction, the daily COP was multiplied by the PLF factor which was calculated from the integrated PLR per day, following the method in Magraner et al. [4]. The variation of model A with $\mathrm{PLF}=\mathrm{f}(\mathrm{Cd}, \mathrm{Cc})$ is the one closest to the reference output model. On the other hand, the results from model A with $\mathrm{PLF}=\mathrm{f}(\mathrm{Cd})$, present the highest deviation. This is consistent with results in the previous section, which was based on the comparison with integrated hourly COP values.

The simulations performed with model B (Fig. 7) show that the best results are obtained with the instantaneous correction for stand-by losses only $(\mathrm{PLF}=\mathrm{f}(\mathrm{Cd}))$, while the other two model variations lead to an occasional acute underprediction of the COP values.
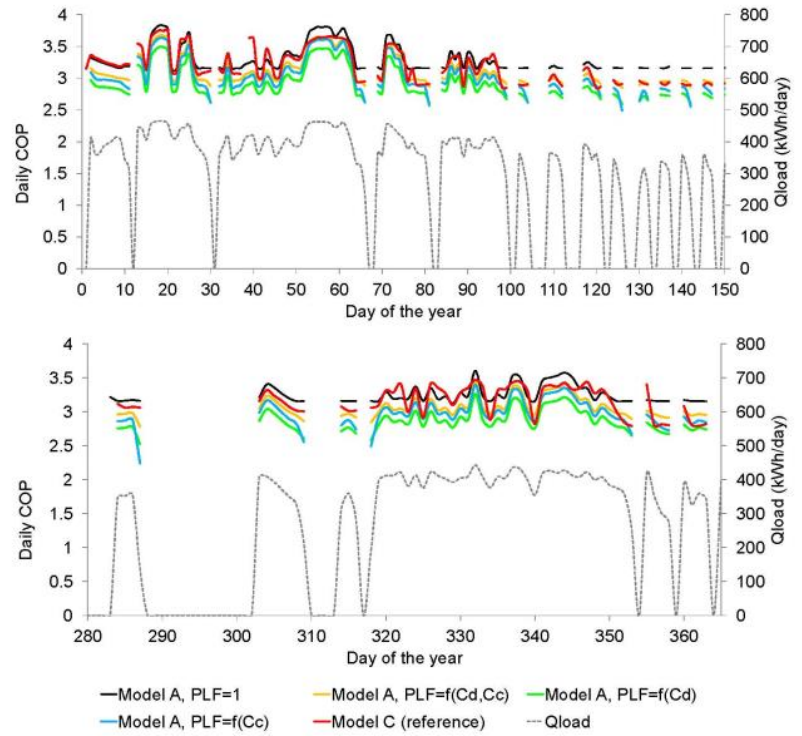

Fig. 6. Daily COP as obtained from annual simulations with variations of model A (Type 927 with PLF hourly postcorrection) and the reference model $\mathrm{C}$ (regression with polynomial activation function).

The instantaneous PLF factor tends to zero for low partial load ratios in the correlations that include $\mathrm{Cc}$, while PLF tends to a value generally above 0.5 in the correction based on $\mathrm{Cd}$ [5]. Hence, the underprediction obtained with correlations based on $\mathrm{Cc}$ is due to an overcorrection effect caused by the application of very low PLF factors during time steps in which the load is very low during cycling.

Table 3 summarizes the performance of models A and B in terms of Root Mean Squared Error (RMSE) calculated on the daily COP profiles (excluding the zero load periods) and the absolute difference between the total annual electrical energy consumption and that of the reference model case $(\Delta$ Pelec). From the previous comparison with experimental COP values it is estimated that the RMSE between the reference model C the experiments is 0.07 . This is adopted as the uncertainty value for the RMSE for comparing the results in Table 3. The best results for both parameters RMSE and $\triangle$ Pelec are obtained for model $\mathrm{B}$ with the instantaneous $\mathrm{Cd}$ correction formula $(\mathrm{PLF}=\mathrm{f}(\mathrm{Cd}))$ followed by model A with post-correction of $\mathrm{PLF}=\mathrm{f}(\mathrm{Cd}$, $\mathrm{Cc})$. While the good performance of model A with $\mathrm{PLF}=\mathrm{f}(\mathrm{Cd}, \mathrm{Cc})$ is consistent with results from the previous section, the result obtained for the instantaneous correction with model $\mathrm{B}$ PLF $=\mathrm{f}(\mathrm{Cd})$ is significantly better than expected from the validation analysis based on the COP integrated per hour. This difference is due to the fact that the final results are sensitive to the periods on which corrections are applied and also to the integration periods used for the analysis of the COP at data post-processing. Hence, while some correlations can produce certain deviations of the COP when analysed on an hourly basis, these deviations may counteract and result in a lower discrepancy with respect 
to the reference model when the COP is integrated on a daily basis.
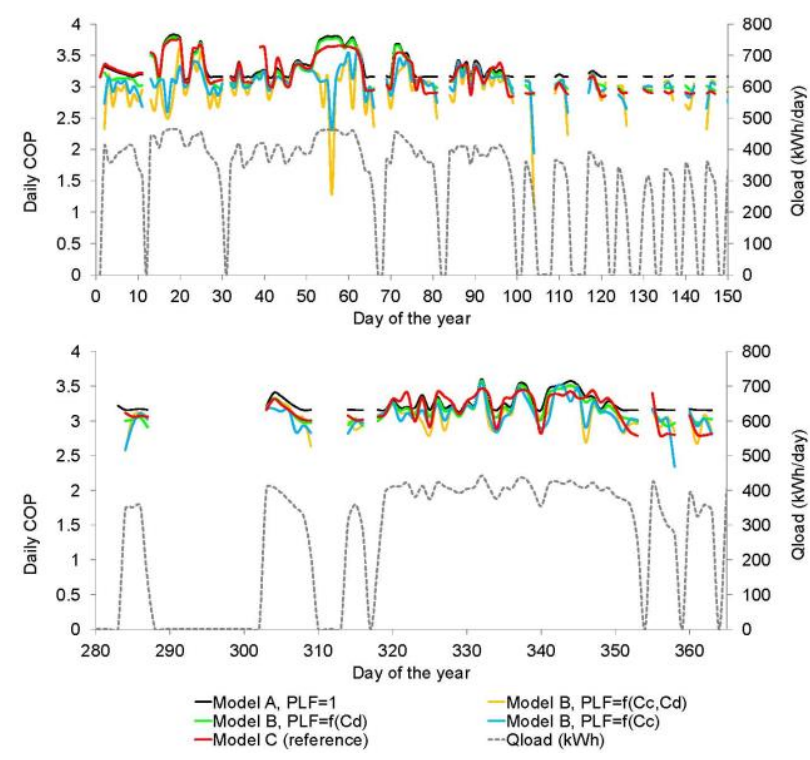

Fig. 7. Daily COP as obtained from annual simulations with variations of model B (Type 927 with instantaneous PLF correction) and the reference model $\mathrm{C}$ (regression with polynomial activation).

It is interesting to note that although the non-corrected model A exhibits a high RMSE value for the daily COP, the integrated electrical energy consumption is very close to the reference. On the other hand the highest deviations for both RSME and the electrical consumption are obtained with model $\mathrm{B}$ when the instantaneous corrections include the $\mathrm{Cc}$ and $\mathrm{Cd}$ factors, which indicates that the selection of the correction equation is very influential on the results.

Table 3. RMSE of daily COP profiles during the year (zero load days excluded) and absolute difference of total annual electrical consumption with respect to reference model case $\mathrm{C}$

\begin{tabular}{|c|c|c|}
\hline Black box model & RMSE & $\begin{array}{c}\Delta \text { Pelec } \\
\text { (kWh/year) }\end{array}$ \\
\hline $\begin{array}{c}\text { Model A, no correction } \\
\text { PLF=1 }\end{array}$ & $0.378 \pm 0.07$ & 507 \\
\hline $\begin{array}{c}\text { Model A, post- } \\
\text { correction PLF=f(Cd) }\end{array}$ & $0.377 \pm 0.07$ & 2134 \\
\hline $\begin{array}{c}\text { Model A, post- } \\
\text { correction PLF=f(Cc) }\end{array}$ & $0.317 \pm 0.07$ & 1300 \\
\hline $\begin{array}{c}\text { Model A, post- } \\
\text { correction } \\
\text { PLF=f(Cc,Cd) }\end{array}$ & $\mathbf{0 . 2 7 0} \pm \mathbf{0 . 0 7}$ & $\mathbf{6 2 7}$ \\
\hline $\begin{array}{c}\text { Model B, } \\
\text { instantaneous } \\
\text { correction PLF=f(Cd) }\end{array}$ & $\mathbf{0 . 2 6 0} \pm \mathbf{0 . 0 7}$ & $\mathbf{1 7 4}$ \\
\hline $\begin{array}{c}\text { Model B, } \\
\text { instantaneous } \\
\text { correction PLF=f(Cc) }\end{array}$ & $0.318 \pm 0.07$ & 2222 \\
\hline $\begin{array}{c}\text { Model B, instantaneous } \\
\text { correction } \\
\text { PLF=f(Cd,Cc) }\end{array}$ & $0.447 \pm 0.07$ & 3951 \\
\hline
\end{tabular}

This study shows that using a detailed transient model such as model $\mathrm{C}$ can provide information of detailed profiles of thermal power and temperatures. However it has been shown also that models such as $\mathrm{A}$ and $\mathrm{B}$, which are based on a simple part load performance correction, can be used to model closely the daily COPs and the annual electrical energy consumption.

Thus, for detailed modelling of thermal power profiles and temperatures it is recommended the use of model $\mathrm{C}$, i.e. a model comprising regression equations for the quasi-steady state, an activation function for the start-up period and a residual electrical power consumption for the stand-by periods. While performance maps from manufacturers allow easily for the construction of regression models, the development of the activation function requires at least a minimum information on the start-up period length. Because the shape of the start-up phase has been found not to be relevant for the results in this study, it is recommended using the exponential startup function that only requires as parameter the characteristic time constant $\tau$ for the start-up period, as this value can be taken from the literature $[5,11]$.

According to the results from this study, simpler alternative options to model $\mathrm{C}$ are valid for modelling the annual performance of a heat pump. These models are based on applying type 927 with post-correction of the integrated COP values based on the experimental coefficients $\mathrm{Cd}$ and Cc. Alternatively, Type 927 combined with instantaneous $\mathrm{Cd}$ default value of 0.25 provides acceptable results of annual COP profiles in the present study. Instantaneous correction, however, should be applied with caution since correlations for COP correction have been derived from integrated energy rather than instantaneous energy rates [5]. In addition, the results are sensitive to the selected periods for correction and integration of the performance values. The influence of these factors should be accounted for in the interpretation of results.

\section{Conclusions}

In this study the performance of different heat pump performance map black box models has been assessed by comparison with experimental data and evaluated on an annual basis. All considered models were comprised of a sub-model for the quasi-steady state phase in combination with functions to account for the influence of the transient stand-by and start-up phases on the performance. Results from the models were compared with experimental values of COP integrated per hour obtained from laboratory testing.

Annual simulations with the different models also allowed comparison of annual performance profiles with respect to a reference model case that was taken as the model that produced best results. In this study it is concluded that the best approach to model in detail the transient behaviour of an on-off heat pump is the use of 
regression models constructed on performance map data along with a start-up activation function and consideration of the residual stand-by consumption. Alternatively, interpolation models like Type 927 provide good estimations when combined with adequate PLF post-processing correction to account for performance losses. The combination of Type 927 with Type 43a based on $\mathrm{Cd}$ for instantaneous correction provides good results in this study, but caution should be taken in its general application because the results are sensitive to the periods of correction (time steps) and the data integration period chosen for the analysis of the COP.

\section{References}

1. T. Afjei, R. Dott, $12^{\text {th }}$ Conference of International Building Performance Simulation Association, Sydney, Australia (2011)

2. TRNSYS 17. "A Transient System Simulation Program”, Solar Energy Laboratory, University of Wisconsin, Madison, USA (2010)

3. TESS library 17 04, 2010. LLC 22 North Carroll Street Suite 370 Madison, WI 53703 U.S.A (2010)

4. T. Magraner, A. Montero, S. Quilis, J.F. Urchueguia Energ. Buildings 42, 1394-1401 (2010)

5. E. Fuentes, D.A. Waddicor, J. Salom, Appl. Energy, 179, 778-789 (2016)

6. J. M., Corberán, D. Donadello, I. Martínez-Galván, C. Montagud, Int. J.Refrig., 36, 8 (2013)

7. J. Ruschenburg, T. Cutic, S. Herkel, Energ. Buildings, 84 (2018)

8. Allard, B. M., Kummert M, 12th Conference of International Building Performance Simulation Association, Sydney, Australia, 14-16 November (2011)

9. EN 14825:2016, Air conditioners, liquid chilling packages and heat pumps, with electrically driven compressors, for space heating and cooling. Testing and rating at part load conditions and calculation of seasonal performance (2016).

10. D. A. Waddicor, E. Fuentes, M. Azar, J. Salom Appl. Thermal Eng. 106, 275-285 (2016)

11. J. Ruschenburg, T. Cutic, J. Wapler, M., Miara. 11th IEA Heat Pump Conference, 12-16 May 2014, Montreal (Quebec), Canada (2014) 